\title{
Paradoxical resistance of multiple myeloma to proteasome inhibitors by decreased levels of 195 proteasomal subunits
}

\section{Diego Acosta-Alvear ${ }^{1,2 \dagger}$, Min Y Cho ${ }^{1,2,3}$, Thomas Wild ${ }^{4}$, Tonia J Buchholz ${ }^{5}$, Alana G Lerner ${ }^{5}$, Olga Simakova ${ }^{6}$, Jamie Hahn ${ }^{6}$, Neha Korde ${ }^{7,8}$, Ola Landgren ${ }^{7,8}$, Irina Maric ${ }^{6}$, Chunaram Choudhary ${ }^{4}$, Peter Walter ${ }^{1,2 *}$, Jonathan S Weissman ${ }^{2,3 *}$, Martin Kampmann ${ }^{3,2+\ddagger}$}

${ }^{1}$ Department of Biochemistry and Biophysics, University of California, San Francisco, San Francisco, United States; ${ }^{2}$ Howard Hughes Medical Institute, University of California, San Francisco, San Francisco, United States; ${ }^{3}$ Department of Cellular and Molecular Pharmacology, University of California, San Francisco, San Francisco, United States; ${ }^{4}$ The Novo Nordisk Foundation Center for Protein Research, University of Copenhagen, Copenhagen, Denmark; ${ }^{5}$ Onyx Pharmaceuticals, Inc. an Amgen subsidiary, South San Francisco, United States; ' ${ }^{6}$ Department of Laboratory Medicine, Clinical Center, National Institutes of Health, Bethesda, United States; ${ }^{7}$ Multiple Myeloma Section, Lymphoid Malignancies Branch, National Cancer Institute, Bethesda, United States; ${ }^{8}$ Myeloma Service, Department of Medicine, Memorial Sloan Kettering Cancer Center, New York, New York, United States

*For correspondence: peter@ walterlab.ucsf.edu (PW); Jonathan.Weissman@ucsf. edu (JSW)

'These authors contributed equally to this work

Present address: ${ }^{\ddagger}$ Department of Biochemistry and Biophysics and Institute for Neurodegenerative Diseases, University of California, San Francisco, San Francisco, United States

Competing interests:

See page 16

Funding: See page 16

Received: 16 April 2015

Accepted: 31 August 2015

Published: 01 September 2015

Reviewing editor: Raymond J Deshaies, Howard Hughes Medical Institute, California Institute of Technology, United States

cc) This is an open-access article, free of all copyright, and may be freely reproduced, distributed, transmitted, modified, built upon, or otherwise used by anyone for any lawful purpose. The work is made available under the Creative Commons CCO public domain dedication.
Abstract Hallmarks of cancer, including rapid growth and aneuploidy, can result in non-oncogene addiction to the proteostasis network that can be exploited clinically. The defining example is the exquisite sensitivity of multiple myeloma (MM) to $20 \mathrm{~S}$ proteasome inhibitors, such as carfilzomib. However, MM patients invariably acquire resistance to these drugs. Using a next-generation shRNA platform, we found that proteostasis factors, including chaperones and stress-response regulators, controlled the response to carfilzomib. Paradoxically, 195 proteasome regulator knockdown induced resistance to carfilzomib in MM and non-MM cells. $19 \mathrm{~S}$ subunit knockdown did not affect the activity of the $20 \mathrm{~S}$ subunits targeted by carfilzomib nor their inhibition by the drug, suggesting an alternative mechanism, such as the selective accumulation of protective factors. In MM patients, lower $19 \mathrm{~S}$ levels predicted a diminished response to carfilzomib-based therapies. Together, our findings suggest that an understanding of network rewiring can inform development of new combination therapies to overcome drug resistance. DOI: 10.7554/eLife.08153.001

\section{Introduction}

Protein degradation by the ubiquitin-proteasome system (UPS) fulfills essential roles in eukaryotic cells in maintaining proteome homeostasis (proteostasis), signaling, and cell cycle progression. The $26 \mathrm{~S}$ proteasome is a large macromolecular machine composed of the $20 \mathrm{~S}$ catalytic core and the $19 \mathrm{~S}$ regulator, each comprised of more than a dozen different protein subunits. The $19 \mathrm{~S}$ proteasome regulator binds polyubiquitinated proteins and catalyzes their deubiquitination and delivery to the $20 \mathrm{~S}$ proteasome core for proteolysis. The $20 \mathrm{~S}$ core proteasome can also associate with alternative proteasome regulators, such as the 11S complex (Nathan et al., 2013; Schmidt and Finley, 2014). 
eLife digest Cells have several mechanisms for removing proteins that have been damaged or are no longer needed. One of these mechanisms is carried out by a large protein complex called the proteasome. Drugs that block the proteasome are toxic to all cells, and a type of blood cancer called multiple myeloma is particularly sensitive to these 'proteasome inhibitors'. However, tumors in patients with multiple myeloma can also become resistant to these drugs.

Using a genetic approach, Acosta-Alvear et al. identified the factors that control the sensitivity of cells to proteasome inhibitors. In particular, reducing the levels of other factors that contribute to protein balance made the cells more sensitive. Using a combination of proteasome inhibitors and drugs that target these other factors could prove to be useful in the fight against multiple myeloma.

The proteasome complex contains two types of subunits: regulatory subunits that recognize the proteins that need to be degraded, and catalytic subunits that degrade the proteins. The results of Acosta-Alvear et al. revealed how varying the levels of these two subunits influenced the sensitivity of cells to inhibitors. While decreasing the levels of catalytic subunits made the cells more sensitive, as expected, decreasing the level of regulatory subunits surprisingly made the cells resistant to the inhibitors. A possible explanation for this paradoxical result is that certain proteins are less effectively degraded by the proteasome in these cells, and that the buildup of these proteins protects the cells against the drugs.

Acosta-Alvear et al. also found that lower levels of regulatory subunits desensitized multiple myeloma patients to therapy based on proteasome inhibition, suggesting that results from the genetic screen carried out in cells can predict clinical resistance mechanisms and guide the development of future therapies to increase patient survival.

DOI: 10.7554/eLife.08153.002

As expected because of its essential cellular role, pharmacologic inhibition of the proteasome is inherently toxic. Consequences of proteasome inhibition leading to toxicity include the accumulation of proteasome substrates and the failure to recycle amino acids (Suraweera et al., 2012). Intriguingly, multiple myeloma (MM) cells are hypersensitive to proteasome inhibition, and two inhibitors of the proteolytic activity of the $20 \mathrm{~S}$ core, bortezomib and carfilzomib, have been approved for the treatment of MM patients (Shah and Orlowski, 2009; Buac et al., 2013; Röllig et al., 2014). The basis for the hypersensitivity of MM cells to proteasome inhibitors is unclear. One hypothesis poses that the high protein biosynthetic rate coupled the high secretory activity of the plasma cell-like MM cells results in an increased need for clearance of misfolded proteins by the proteasome (Meister et al., 2007; Bianchi et al., 2009; Cenci et al., 2012). This would render these cells heavily dependent on the proteasome and the proteostasis network at large, and would account for the therapeutic window of proteasome inhibitors in the clinic.

Most MM patients initially respond to treatment with proteasome inhibitors, but the tumors eventually develop resistance (Buac et al., 2013). To uncover the genetic mechanisms underlying resistance to proteasome inhibitors, and to identify strategies to overcome resistance, we used our next-generation shRNA library (Kampmann et al., 2015) to screen for genes controlling the sensitivity and adaptation of MM cells to the proteasome inhibitor carfilzomib.

Paradoxically, we found that knockdown of $19 \mathrm{~S}$ regulator components desensitized cells to proteasome inhibition. Previous RNAi screens had not reported this effect (Chen et al., 2010; Zhu et al., 2011), however a haploid mutagenesis screen carried out independently and in parallel to this study also found the protective effect of 19S depletion (S. Lindquist, personal communication). Lower 19S levels were also predictive of diminished response of MM patients to proteasome inhibitorbased therapy.

\section{Results}

\section{Identification of genes controlling sensitivity to proteasome inhibitors}

To identify genetic nodes that would delineate specific dependencies of MM cells, as well as those controlling the response of MM cells to proteasome inhibitors, we conducted an RNAi screen using our next-generation shRNA library (Kampmann et al., 2015). This library targets each mRNA by 25 
independent shRNAs and contains thousands of negative control shRNAs to enable robust detection of hit genes. We introduced sublibraries targeting 7712 genes involved in proteostasis, cancer, apoptosis, kinases, phosphatases and drug targets into U-266 MM cells. We then split this population into two subpopulations, each of which was grown either in the absence of drug or exposed to 1-hr pulses of carfilzomib followed by recovery (Figure 1A). This strategy allows for the identification of inherent vulnerabilities (i.e. genes affecting cell growth), as well as genes controlling sensitivity to proteasome inhibition. We identified several hundred genes that modified the response (either

A

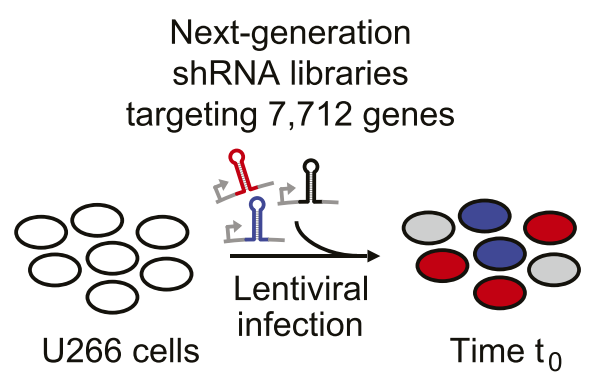

shRNA libraries

argeting 7,712 genes

266 cells$$
\text { (1) }
$$

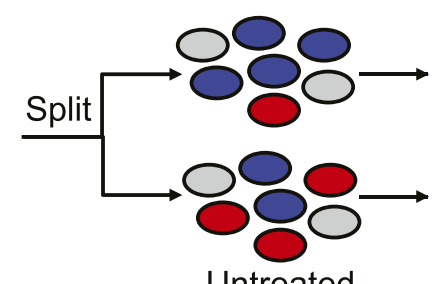

Untreated
4 pulses of carfilzomib followed by recovery

B

$$
\text { FDR-corrected }-\log _{10} P \text { value, for GO term enrichment }
$$

0

Proteasome core complex

Threonine-type peptidase activity

Proteasome complex

Proteasomal protein catabolic process

Negative regulation of cellular protein metabolic process

Ubiquitin-dependent protein catabolic process

Cellular macromolecule catabolic process

Proteasome complex

Proteasomal protein catabolic process

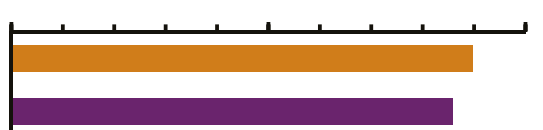

Frequencies of cells expressing each shRNA
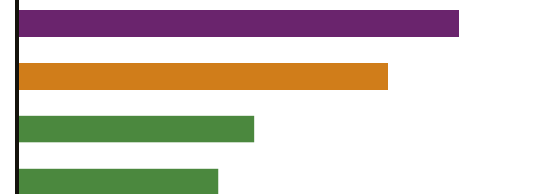

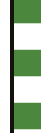

Translation

Mitotic cell cycle

Positive regulation of cellular protein metabolic process

Regulation of cellular protein metabolic process

Ubiquitin-dependent protein catabolic process

Cytosol

Translation factor activity, nucleic acid binding

Positive regulation of macromolecule metabolic process

Cell cycle

GO category: Biological process Cellular component Molecular function

Figure 1. Screen for genes controlling the sensitivity of multiple myeloma cells to carfilzomib. (A) Screening strategy. (B) Gene Ontology (GO) categories enriched among the top 50 genes whose depletion results in sensitization carfilzomib and the top 50 genes whose depletion results in desensitization carfilzomib. DOI: 10.7554/eLife.08153.003 
sensitizing or desensitizing) towards carfilzomib, as well as several hundred genes whose loss impacted cell growth (Supplementary files 1 and 2). Gene Ontology (GO) term enrichment analysis of the hit genes from this primary screen identified the UPS, cell cycle, and translation as major functional categories controlling the cells' response towards proteasome inhibition (Figure 1B).

\section{Nodes within the proteostasis network control the response to proteasome inhibition}

As expected, the genetic depletion of the multi-drug resistance $A B C$ transporters ( $A B C B 1$, black circle in Figure 2A) sensitized cells to carfilzomib. In addition, several nodes of the cytosolic proteostasis network modulated sensitivity to proteasome inhibition, including molecular chaperones (HSPA4,

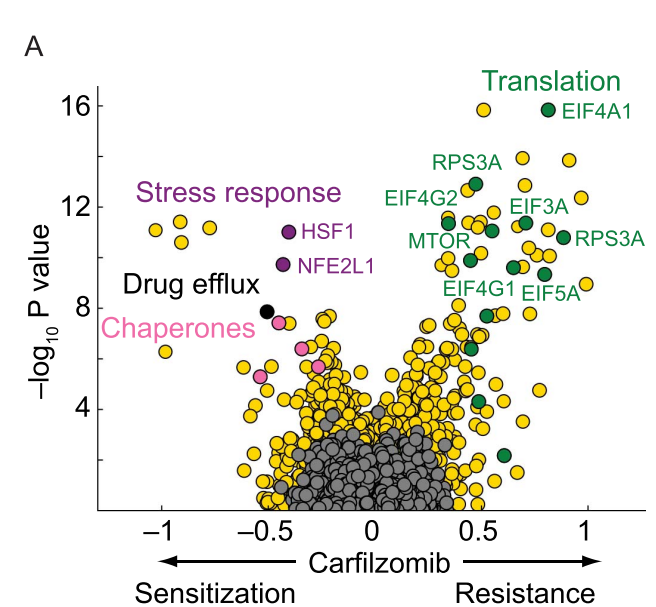

B

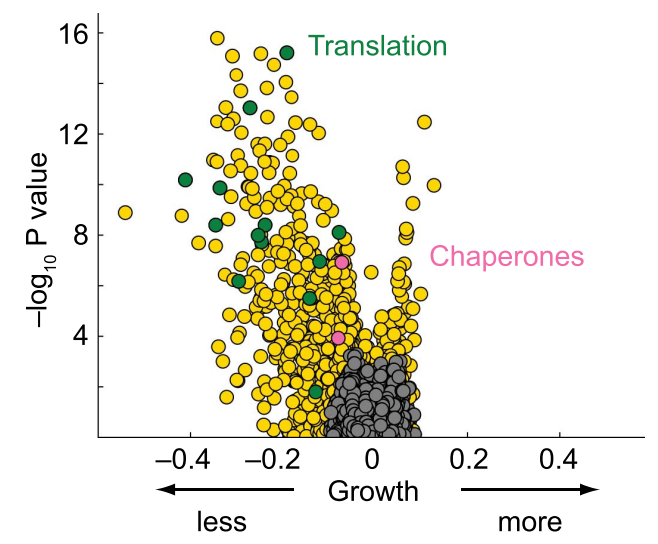

C

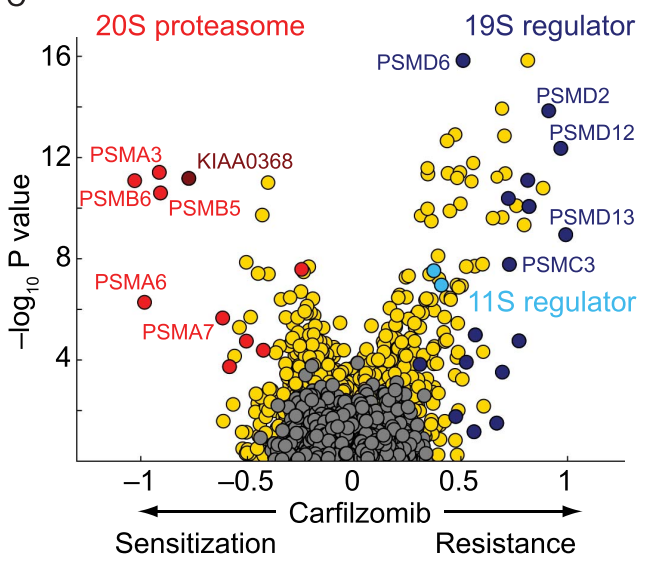

D

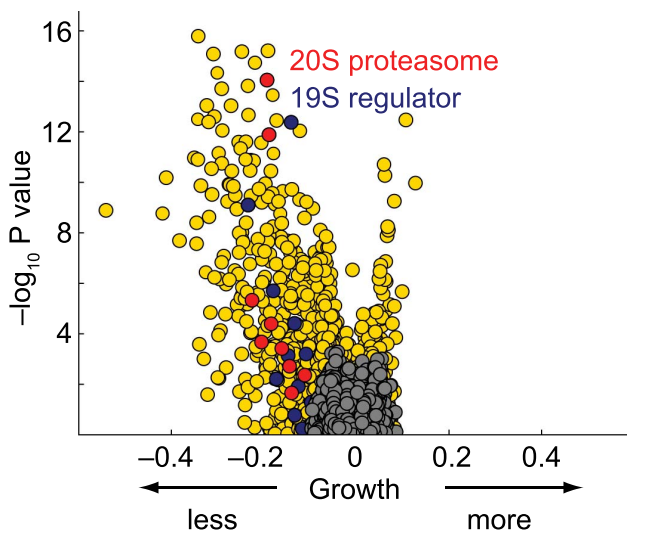

Figure 2. Nodes within the proteostasis network control the response of myeloma cells to carfilzomib. (A) Volcano plot showing knockdown effects (sensitization or desensitization to carfilzomib) and statistical significance of human genes (orange dots) and quasi-genes generated from negative control shRNAs (grey dots). Drug resistance / sensitization phenotypes were previously defined as $\rho$ (Kampmann et al., 2013); a value of -1 corresponds to a twofold sensitization to the drug. Hit genes belonging to functional categories of interest are color-coded as labeled in the panels. (B) Volcano plot as in $\mathbf{A}$, except showing effect on growth. Growth phenotypes were previously defined as $\gamma$ (Kampmann et alo, 2013); a value of -1 corresponds to a twofold reduction in growth rate. (C) Volcano plot as in A, highlighting the opposing effects of $20 \mathrm{~S}$ or $19 \mathrm{~S}$ proteasome knockdown on the sensitivity of cells towards carfilzomib. Note the protective effect is not restricted to the 19S regulator alone, but is shared with the $11 \mathrm{~S}$ regulator. (D) Volcano plot as in $\mathbf{C}$, except showing effect on growth. DOI: 10.7554/eLife.08153.004

The following figure supplement is available for figure 2 :

Figure supplement 1. Comparison of growth phenotypes and carfilzomib resistance phenotypes for each targeted gene. DOI: 10.7554/eLife.08153.005 
HSPA8, HSPA90AB1; pink circles in Figure 2A), and stress response transcription factors (HSF1, NFE2L1; purple circles in Figure 2A). Conversely, knockdown of several genes directly participating in protein synthesis conferred protection (green circles in Figure 2A), most notable including components of the EIF4F translation initiation complex (EIF5A, EIF4A1, EIF4E, EIF4G1, EIF4G2, EIF3A, EIF3F), as well as the elongation factor EEF2, ribosomal RNA polymerase (POLR1D), ribosomal proteins (RPS3A, RPS6, RPS25), and MTOR, the master regulator of protein synthesis, even though knockdown of these factors in the absence of carfilzomib was detrimental to cell growth (Figure 2B). This finding is consistent with the notion that decreased protein synthesis alleviates the load on proteasome (Chen et al., 2010; Cenci et al., 2012).

Some of the relevant nodes of the proteostasis network that we identified can be targeted pharmacologically. Based on the protective effect of MTOR knockdown, we hypothesized that its inhibition by rapamycin would desensitize cells to carfilzomib. Indeed, we observed the expected protective effect of rapamycin (Figure 3). Since MTOR inhibition can also induce autophagy (Reviewed in Sarkar, 2013), we tested whether the MTOR-independent induction of autophagy by trehalose (Sarkar et al., 2007) would confer similar protection. Our results support the protective role of autophagy during proteasome inhibition (Figure 3-figure supplement 1), indicating that MTOR inhibition may desensitize to carfilzomib both through inhibition of translation and induction of autophagy. These experiments illustrate the potential of our functional genomics approach to predict drug-drug interactions on the cellular level.

\section{Paradoxical phenotype of 195 knockdown}

Knockdown of several subunits of the $20 \mathrm{~S}$ proteasome core itself (PSMB1, PSMB4, PSMB5, PSMB6, PSMA2, PSMA3, PSMA7, red circles in Figure 2C), as well as genetic depletion of KIAA0368/ECM29 (brown circle in Figure 2C), an adaptor/scaffold protein that associates with the $20 \mathrm{~S}$ core (Gorbea et al., 2004), and NFE2L1 (purple circle in Figure 2A), a transcription factor controlling proteasome biogenesis (Radhakrishnan et al., 2010; Steffen et al., 2010), provided strong sensitization to proteasome inhibition. This finding is consistent with previous studies in which depletion of a protein or pathway targeted by a drug sensitizes cells to the drug used around its EC50 (Giaever et al., 1999; Matheny et al., 2013).

Unexpectedly, the genetic depletion of the vast majority of subunits of the $19 \mathrm{~S}$ proteasomal regulator conferred marked resistance to proteasome inhibition (blue circles in Figure 2C). Notably, $19 \mathrm{~S}$ subunits were among the strongest protective hits in our screen (Supplementary file 2). This paradoxical effect also occurred with the depletion of PSME1 and PSME2, components of the 11S regulator (light blue circles in Figure 2C). While knockdown of 20S and 19S subunits in the presence of carfilzomib had opposing phenotypes, knockdown of either 195 or $20 \mathrm{~S}$ subunits in the absence of carfilzomib negatively impacted cell growth in all cases (Figure 2D). However, the protective effect of $19 \mathrm{~S}$ knockdown was not simply mediated by slowing cell growth, since knockdown of many other genes had a similar or more dramatic impact on cell growth without increasing resistance to carfilzomib (Figure 2C,D, Figure 2-figure supplement 1, Supplementary files 1 and 2).

The opposing protective and sensitizing effects of $19 \mathrm{~S}$ and $20 \mathrm{~S}$ subunit knockdown were observed for the vast majority of shRNAs targeting these genes (Figure $4 A, B$ ). To validate the generality of our findings, we determined bortezomib sensitivity in a batch retest of shRNAs introduced into JJN-3, U-266, and RPMI-8226 MM cells, and K-562 leukemia cells. As we observed in U-266 cells treated with carfilzomib, knockdown of $20 \mathrm{~S}$ subunits sensitized to proteasome inhibitors, whereas knockdown of $19 \mathrm{~S}$ subunits desensitized to proteasome inhibition across this cell line panel (Figure 4C). In addition, we introduced single shRNAs into MM cells targeting single subunits of either the $20 \mathrm{~S}$ core or $19 \mathrm{~S}$ regulator. In these experiments, expression of the individual shRNAs resulted in about twofold shifts of the dose-response curves to proteasome inhibition (Figure 4D), lending further strong support to the results from the genetic screen.

\section{Depletion of 195 regulator subunits does not desensitize the 205 core to inhibitors}

To gain insights into the mechanistic basis of the protective effect of 195 knockdown, we first tested whether depletion of $19 \mathrm{~S}$ subunits changed $20 \mathrm{~S}$ levels or protects the $20 \mathrm{~S}$ core from proteasome inhibitors. To this end, we compared the chymotrypsin-like protease activity of the $\beta 5$ subunits of the 


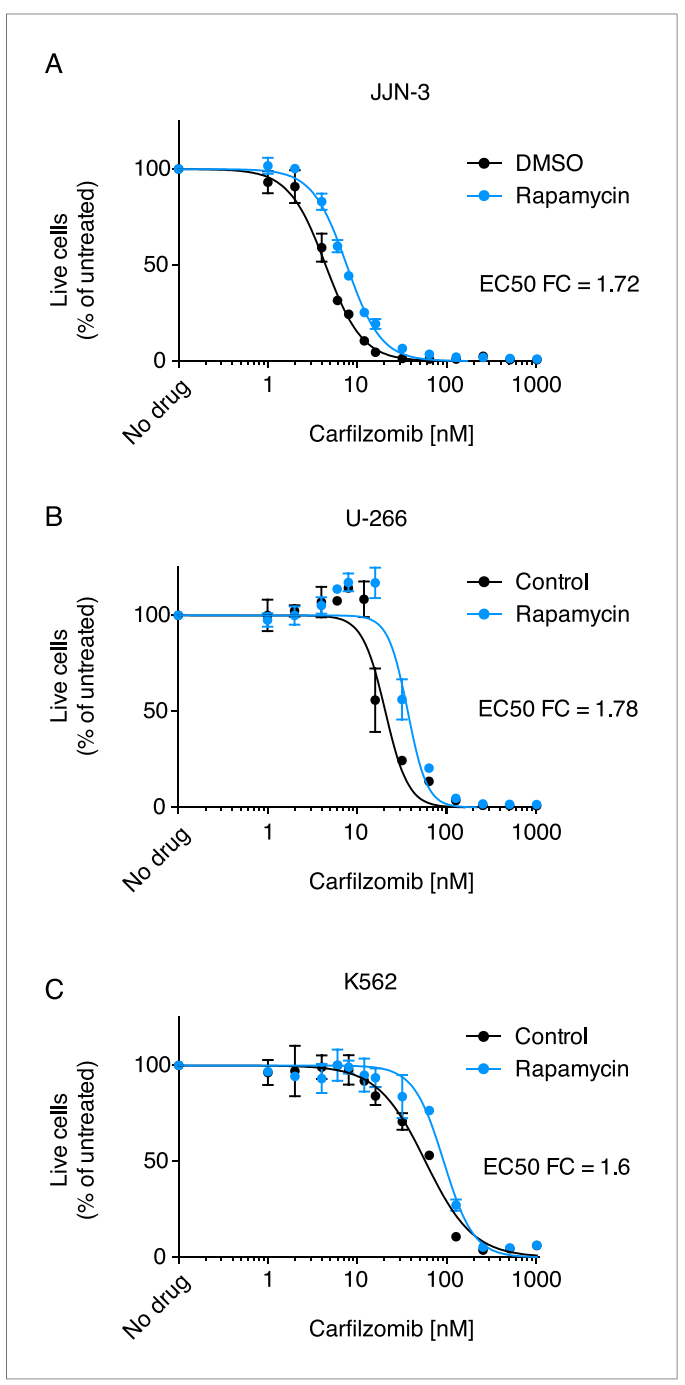

Figure 3. Rapamycin desensitizes cells to carfilzomib Dose-response curves of multiple myeloma (MM) cells (A, B) and a leukemia cell line (C) exposed to carfilzomib after a $24 \mathrm{hr}$ pretreatment with $200 \mathrm{nM}$ rapamycin. FC: fold change of EC50. Data points are means of two experimental replicates, error bars denote SD. DOI: 10.7554/eLife.08153.006

The following figure supplement is available for figure 3 :

Figure supplement 1. Induction of autophagy desensitizes cells to carfilzomib. DOI: 10.7554/eLife.08153.007
$20 \mathrm{~S}$ core (which is the direct target of carfilzomib and bortezomib) in lysates of cells expressing a negative control shRNA or an shRNA targeting the 195 subunit PSMD12 (characterized in Figure 5-figure supplement 1). We found that PSMD12 knockdown did not substantially increase $20 \mathrm{~S}$ chymotrypsin-like activity, and did not affect its susceptibility to carfilzomib (Figure 5A). We confirmed these findings by an orthogonal approach measuring the amounts of accessible $20 \mathrm{~S}$ subunits targeted by carfilzomib ( $\beta 5$ and LMP7) in a proteasome constitutive/immunoproteasome subunit enzyme-linked immunosorbent assay, ProCISE (Parlati et alo, 2009) (Figure 5B,C). Together, these results suggest that the loss of $19 \mathrm{~S}$ subunits does not lead to a decreased effectiveness of proteasome inhibitors in targeting and inhibiting the $20 \mathrm{~S}$ core.

\section{Depletion of the 195 regulator subunits causes changes in the spectrum of proteasome substrates}

Our results support a scenario wherein the catalytic activity of the $20 \mathrm{~S}$ core and its sensitivity to proteasome inhibitors remains unaltered in the face of 195 depletion. Therefore, we reasoned that knockdown of 195 subunits causes profound changes to cellular physiology that desensitize cells to the effects of proteasome inhibition. Because the $19 \mathrm{~S}$ regulator delivers substrates to the 20 S catalytic core (Liu and Jacobson, 2013), we hypothesized that a loss in 195 function may lead to the selective accumulation of certain proteins, some of which may mitigate the effects of $20 \mathrm{~S}$ core inhibition.

To determine the global effects of 195 knockdown on the proteome, we conducted an exploratory proteomics experiment that suggested a possible accumulation of select substrates (Figure 6-figure supplement 1, Supplementary files 3 and 4). Among the proteins accumulating upon 195 knockdown were protein degradation factors, whose accumulation we verified by quantitative immunoblot (Figure 6). These included SOSTM1/p62, a cargo receptor protein that delivers polyubiquitylated proteins to aggresomelike bodies degraded by the autophagosome (Pankiv et alo, 2007), and two subunits of a heterotrimeric complex functioning in endoplasmic reticulum (ER)-associated protein degradation: UFD1L and the triple AAA ATPase VCP/p97 (Wolf and Stolz, 2012). Notably, these factors accumulated upon PSMD12 knockdown both in the presence and absence of carfilzomib, but not (or to a lesser degree) upon carfilzomib treatment (Figure 6).

By contrast, the abundance of the anti-apoptotic Bcl-2 family member MCL1, a protein rapidly turned over by the proteasome (Schwickart et al., 2010), was sharply increased by carfilzomib treatment, but much less affected by 195 knockdown (Figure 6). Similarly, 195 knockdown did not 
A

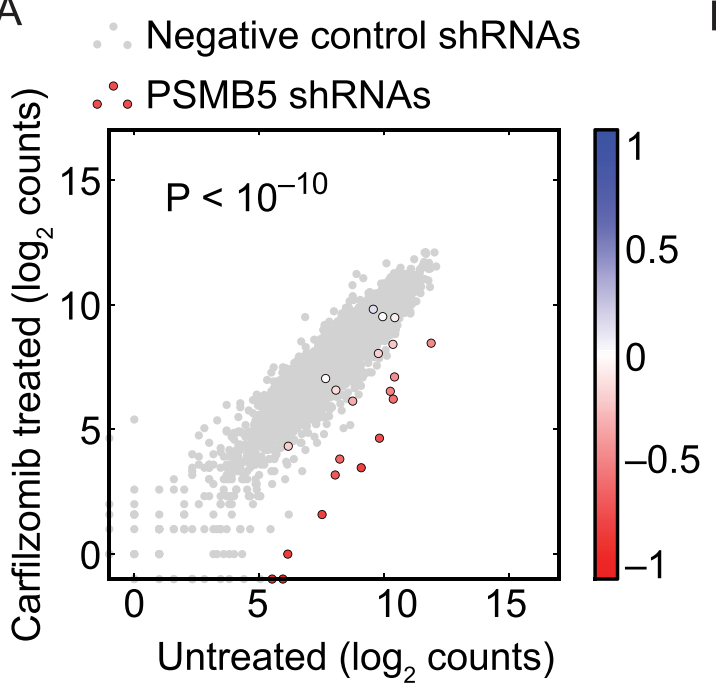

C
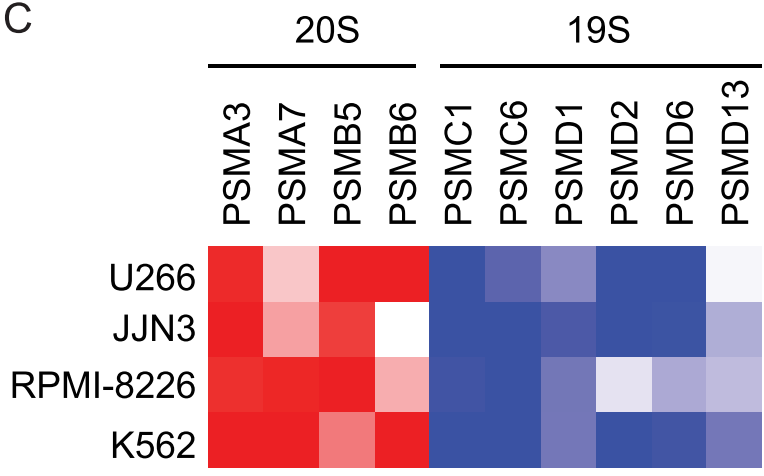

B

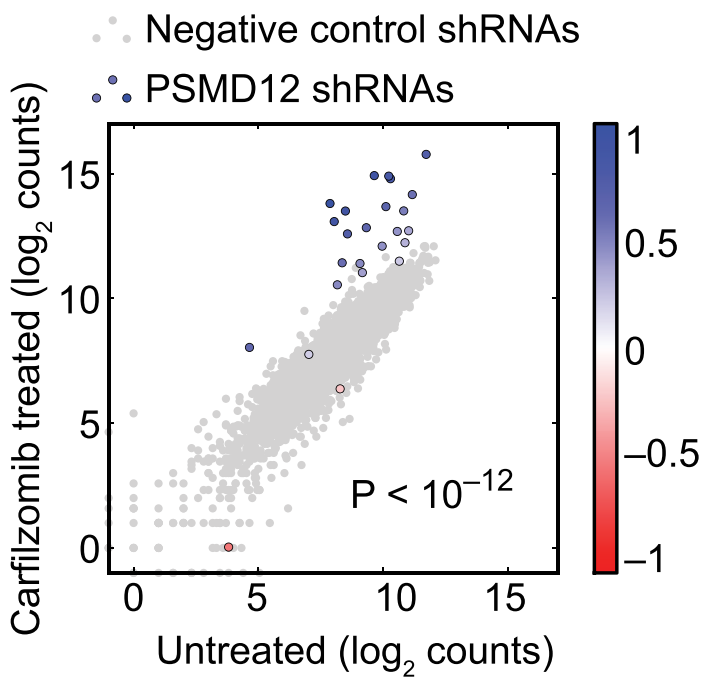

Bortezomib

sensitivity
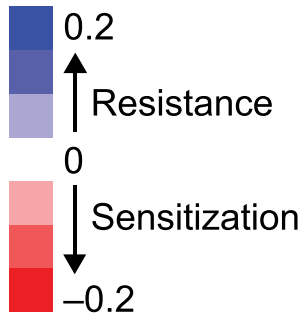

D

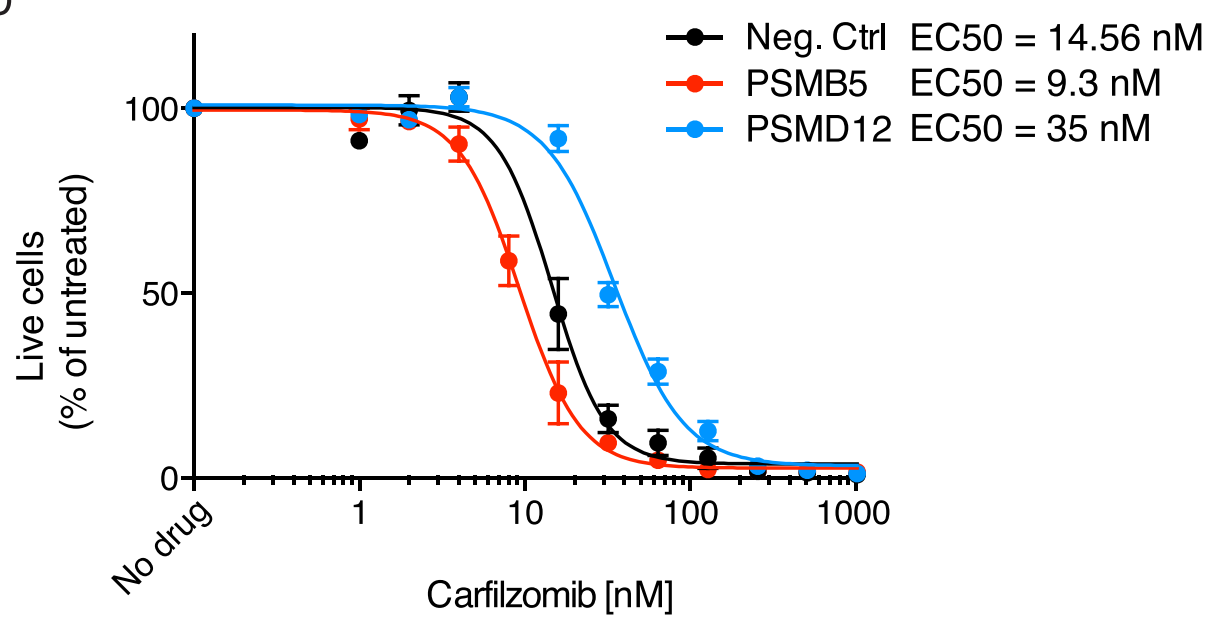

Figure 4. Opposing effects of $19 \mathrm{~S}$ and $20 \mathrm{~S}$ proteasomal subunit knockdown on carfilzomib sensitivity. (A, B) Scatter plots of the frequencies cells expressing different shRNAs targeting a $20 \mathrm{~S}$ core subunit (A) or a $19 \mathrm{~S}$ regulator subunit (B) in untreated or carfilzomib-treated cells. The grey dots represent cells expressing negative control shRNAs. Colored bars indicate the quantitative resistance phenotype ( $\rho$ ) of each shRNA. (C) Heatmap showing the protective or sensitizing effect of knocking down subunits of the 19S or 20S proteasomes, respectively, in multiple cell lines. (D) Dose-response of U266 cells that constitutively expresses an shRNA targeting the PSMD12 subunit of the 19S proteasome, the PSMB5 subunit of the $20 \mathrm{~S}$ proteasome, or a negative control shRNA. Data points are means of two experimental replicates, error bars denote SD.

DOI: 10.7554/eLife.08153.008 


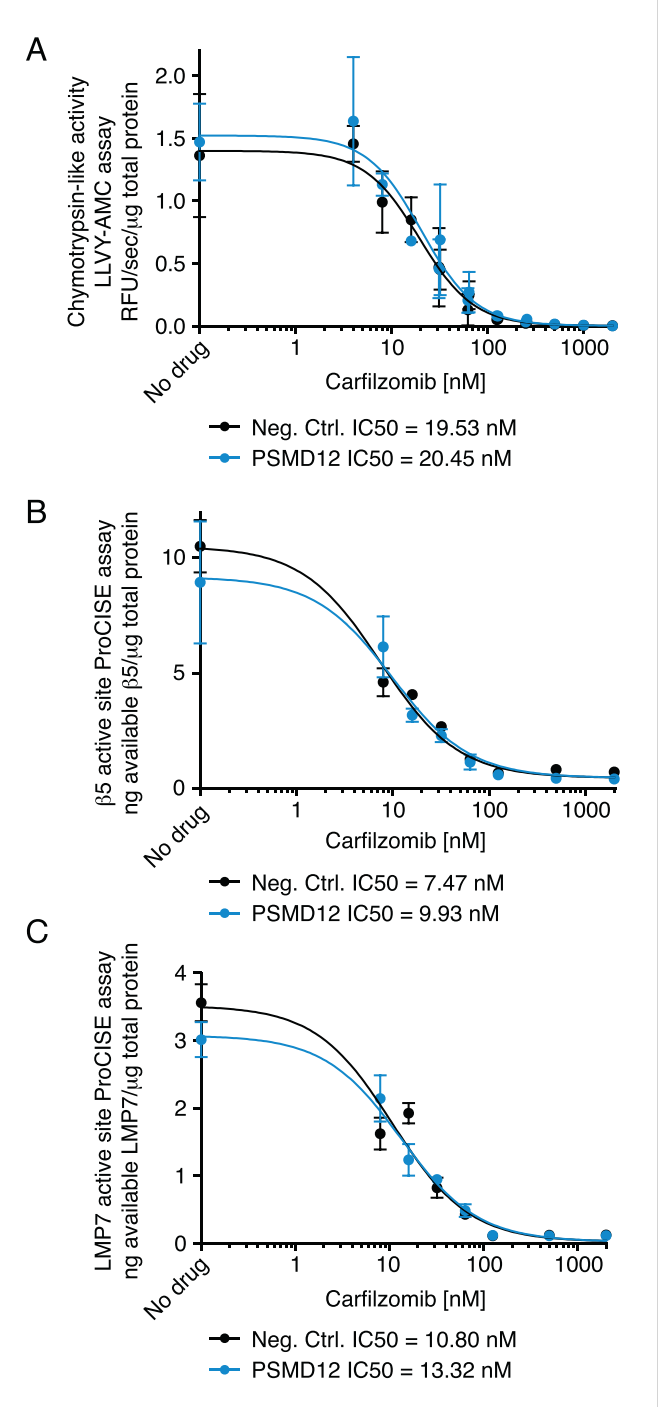

Figure 5. Proteasome activity in U266 cells expressing a negative control shRNA or an shRNA targeting the PSMD12 subunit of the 195 proteasome, and its susceptibility to inhibition by carfilzomib after a $1 \mathrm{hr}$ treatment. (A) Fluorometric measurement of the chymotrypsin-like protease activity of the $20 \mathrm{~S}$ proteasome. (B, C) Enzyme-linked immunoabsorbent assay for accessibility of the (B) $\beta 5$ subunit and the (C) LMP7 subunits of the $20 \mathrm{~S}$ proteasome. Data points are means of two experimental replicates, error bars denote SD. DOI: 10.7554/eLife.08153.009

The following figure supplement is available for figure 5 :

Figure supplement 1. Characterization of samples used to measure proteasome activity in Figure $\mathbf{5}$. DOI: 10.7554/eLife.08153.010 impact of 195 levels on lenalidomide response, the rapidity and depth of the response in this study (Korde et al., 2015) suggest that anti-tumor activity is mostly due to carfilzomib, since lenalidomide has consistently been reported to act more slowly and have a much lower CR rate than carfilzomib (Mateos et al., 2013).

lead to an overall enhancement of NFkB signaling, a pathway critical for survival and proliferation of lymphoid malignancies (Demchenko and Kuehl, 2010) (Figure 6). A caveat of this comparison is that the PSMD12 knockdown was constitutive, whereas the carfilzomib treatment was acute. Notwithstanding, these observations are consistent with the hypothesis that the protective phenotype we observed upon 19S knockdown may arise from the selective upregulation of protein turnover pathways and not from the upregulation of pro-survival pathways.

\section{The level of 19S proteasome is predictive of MM response to therapy with proteasome inhibitors}

Proteasome inhibitors bortezomib and carfilzomib are used clinically to treat MM patients. Most patients respond to proteasome inhibitors to varying degrees, but eventually develop resistance. We sought to test whether the role of 195 levels in controlling sensitivity to proteasome inhibitors, which we identified in cell lines, would also be relevant in MM patients. To this end, we isolated CD138-positive cells, which include MM cells and plasma cells, from the bone marrow cells of pre-treatment $\mathrm{MM}$ patients. Patients then underwent carfilzomib-based combination therapy. Using previously defined criteria (Durie et al., 2006), we classified patients based on their response to therapy as complete responders (including complete response [CR], and stringent complete response, [sCR]) or partial responders (including partial response [PR], and very good partial response [VGPR]).

Using flow cytometry, we quantified levels of 195 regulator subunit S7 (PSMC2), 20 S core subunit beta-4 (PSMB2) and aggresomes in pretreatment CD138-positive cells. We found that $19 S$ proteasome levels were significantly higher in the group of patients who achieved CR after treatment compared to partial responders ( $p<0.0007$, Mann-Whitney test; Figure 7A). By contrast, levels of the 20S core proteasomes were not significantly different between complete and partial responders (Figure 7B). Similarly, aggresome levels were not predictive of clinical outcomes (Figure 7C). The combination therapy used in the clinical study included lenalidomide, and while we cannot exclude an 


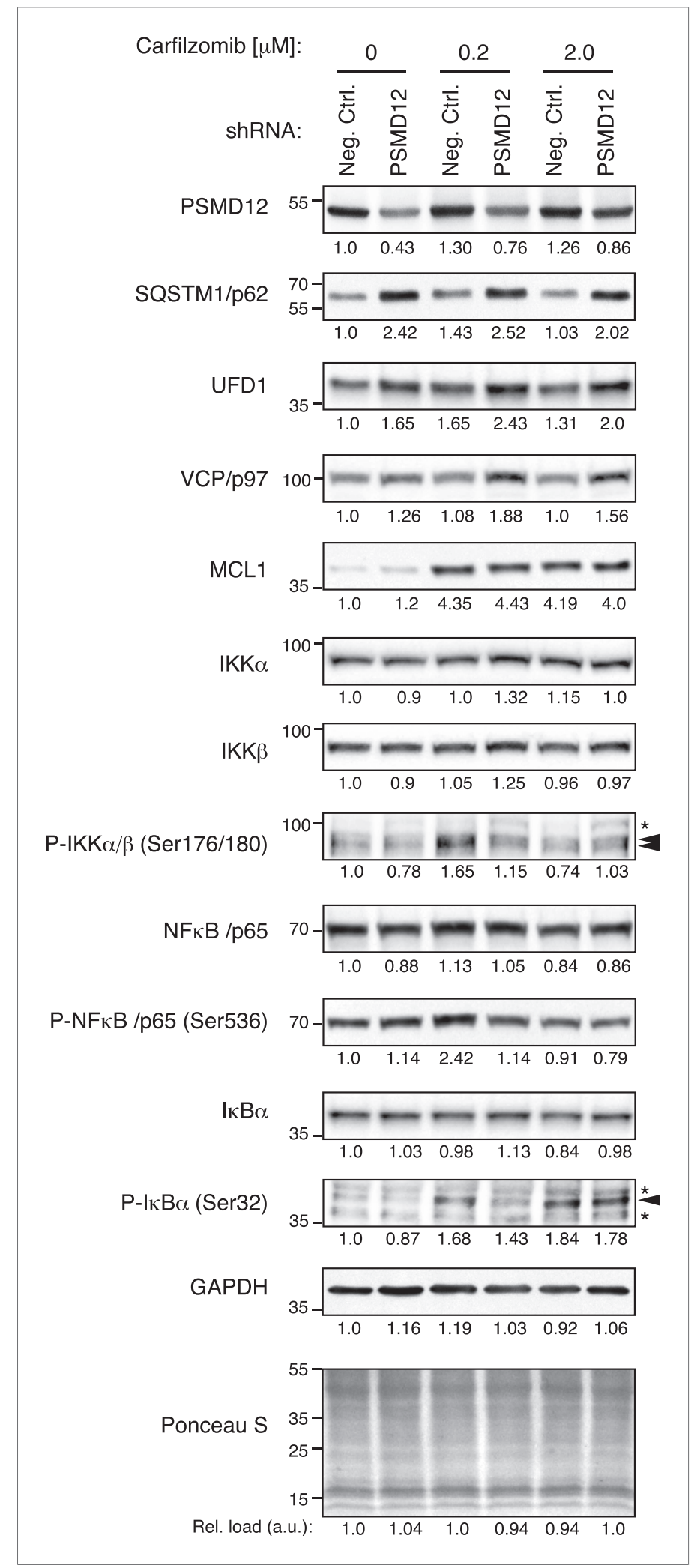

Figure 6. Depletion of the $19 \mathrm{~S}$ protease regulator causes the accumulation of specific substrates. Immunoblot analysis of protein levels in U-266 cells expressing a negative control shRNA or an shRNA targeting 19S subunit PSMD12, untreated or exposed to low $(200 \mathrm{nM})$ or moderate doses $(2 \mu \mathrm{M})$ of carfilzomib for $4 \mathrm{hr}$. Numbers below the Figure 6. continued on next page 
Figure 6. Continued

blots correspond to the normalized relative amount (compared to total protein in each lane). Numbers on the left margin of each panel indicate molecular weights $(\mathrm{kDa})$.

DOI: 10.7554/eLife.08153.011

The following figure supplement is available for figure 6:

Figure supplement 1. Determination of the global effects of 195 proteasome depletion on the proteome. DOI: 10.7554/eLife.08153.012

Taken together, these findings suggest that the desensitization to proteasome inhibition caused by decreased $19 \mathrm{~S}$ levels is also clinically relevant in MM patients, and that $19 \mathrm{~S}$ levels are a predictive biomarker of response to proteasome inhibitor-based therapy.

\section{Discussion}

The exquisite sensitivity of MM cells to proteasome inhibitors provides a paradigm for non-oncogene addiction in cancer. Using our next-generation RNAi platform to identify genetic determinants of sensitivity to proteasome inhibitors, we found that incapacitating the 'executioner' (the 20S core) promotes sensitization to the pharmacological insult, while disarming the 'decision maker' (the 19S regulator) paradoxically results in resistance. In fact, knockdown of almost any 19S subunit conferred carfilzomib resistance, and together they were the group of genes with the strongest protective effect. These opposing phenotypes are consistent with our previous observations in budding yeast, where components of the $20 \mathrm{~S}$ and $19 \mathrm{~S}$ proteasome subcomplexes formed separate functional clusters in a genetic interaction map (Breslow et al., 2008).

The phenotype arising from genetic depletion of the $20 \mathrm{~S}$ core subunits is readily understandable and in line with previous observations: diminishing the amount of the direct target of an inhibitory drug sensitizes cells to the drug (Giaever et al., 1999; Matheny et al., 2013). Two non-mutually exclusive scenarios account for this observation: silencing the 205 core subunits can lead to (i) a crippled proteasome that is easier to inhibit, or to (ii) substoichiometric amounts of the silenced subunits which in turn compromises the assembly of functional proteasomes.

The protective effect of $19 \mathrm{~S}$ regulator knockdown was unexpected since $19 \mathrm{~S}$ and $20 \mathrm{~S}$ work in concert to degrade ubiquitylated protein substrates. We validated our finding in a range of $\mathrm{MM}$ and non-MM cells with different genetic backgrounds, as well as in MM patients, suggesting this is a general, unifying mechanism underlying the response and adaptation to proteasome inhibition. Our data supports that $19 \mathrm{~S}$ depletion alters the spectrum of proteasome substrates, leading to selective accumulation of factors involved in protein degradation. This mechanism may represent a homeostatic feedback loop that is relevant in normal cellular contexts. In MM cells, upregulation of protein turnover pathways may reduce cellular dependence on the proteasome.

Previously reported mechanisms of resistance to proteasome inhibitors in yeast and mammalian cells include mutations or overexpression of the direct drug target, PSMB5, in the catalytic core of the proteasome (Oerlemans et al., 2008; Huber et al., 2015), but to our knowledge, they have never been identified in patients. Our results support an entirely different mechanism of drug resistance, brought about by rewiring the proteostasis network, which reduces the dependence on the proteasome. A detailed understanding of the role of the proteostasis network in disease remains a major challenge. This is due to the size of the network its dynamic nature, genetic redundancies, and context dependence (Balch et al., 2008). Our functional genomics approach proved to be especially well-suited to reveal functionally relevant nodes contributing to the rewiring of the proteostasis network in the context of disease.

The notion that alternative protein degradation pathways can desensitize cells to proteasome inhibitors provides a strong motivation for the simultaneous targeting of parallel pathways in combination therapy. Indeed, other groups have investigated the role of autophagy during proteasome inhibition (Kawaguchi et al., 2011; Santo et al., 2012; Komatsu et al., 2013; Moriya et al., 2013; Mishima et al., 2015), and combinations of bortezomib with autophagy inhibitors, including hydroxychloroquine (Vogl et al., 2014) and the HDAC6 inhibitor ACY-1215 (ClinicalTrail.gov identifier NCT01323751), are currently in clinical trials for MM.

While increasing protein degradation desensitizes cells to proteasome inhibition, our results also suggest and are consistent with an alternative network-level mechanism of resistance: reducing 


\section{A 195 subunit S7 (PSMC2)}

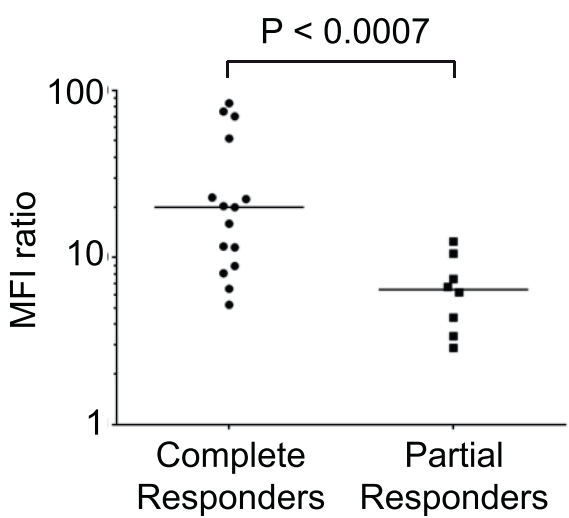

B 20S subunit $\beta 4$ (PSMB2)

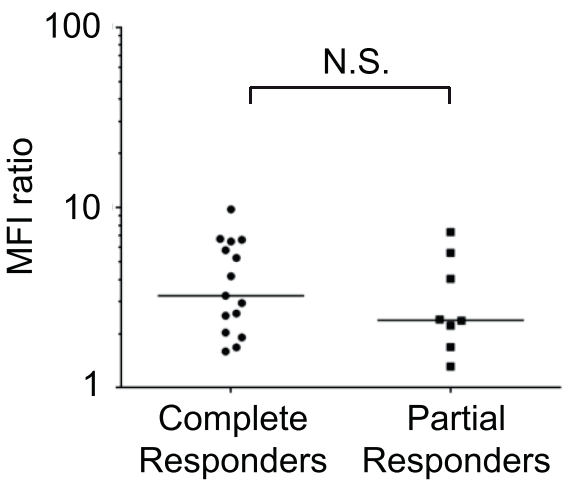

C Aggresome

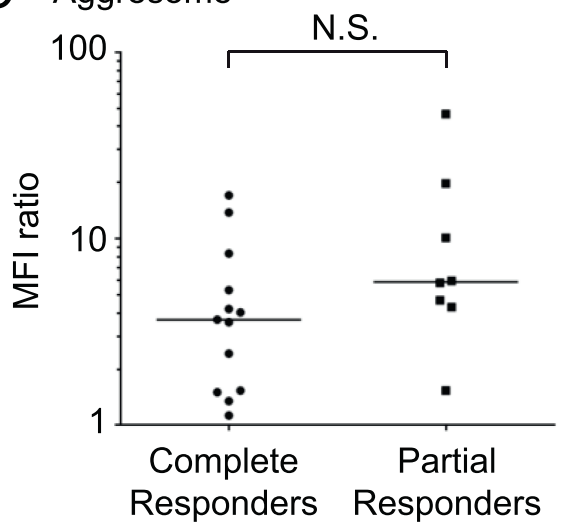

Figure 7. $19 \mathrm{~S}$ proteasomal subunit levels predict the response to carfilzomib-based therapy in patients. Levels of (A) 195 subunit PSMC2, (B) 20S subunit PSMB2 and (C) aggresomes quantified by flow cytometry in CD138 + bone marrow cells (including plasma cells and MM cells) of patients prior to therapy in clinical trial for carfilzomib-based combination therapy. Values are shown for separately for complete responders and partial responders.

DOI: 10.7554/eLife.08153.013 protein synthesis (Chen et al., 2010; Cenci et al., 2012). Both mTOR and the EIF4F complex are master regulators of protein synthesis, and their depletion leads to increased resistance towards proteasome inhibition. By diminishing protein synthesis, the cell could remodel its response to proteasome inhibitors, in this case not through the compensatory upregulation of alternative protein degradation pathways, but by offsetting the reduced proteasome capacity through lowered protein load.

Our functional genomics approach also pointed to other nodes in the proteostasis network that emerge as synergistic vulnerabilities with proteasome inhibition. Specifically, knockdown of the master regulator of cytosolic proteostasis, HSF1, and of individual cytosolic Hsp70 and Hsp90 chaperones sensitized cells to carfilzomib (Figure 2A). These nodes are therefore additional candidate targets for combination therapy with proteasome inhibitors. Hsp90 inhibitors (Ishii et al., 2012; Suzuki et al., 2015) and Hsp70 inhibitors (Braunstein et al., 2011) have previously been reported to act synergistically with bortezomib against MM cells.

Notably, we did not find a role for ER proteostasis factors in controlling sensitivity to carfilzomib in U-266 cells. The high secretory activity of MM cells had previously been hypothesized to challenge the folding capacity of the $E R$, leading to an increased burden of misfolded protein that would explain the increased dependence on the proteasome (Meister et al., 2007; Bianchi et al., 2009). A possible explanation of our findings is that during proteasome inhibition in MM cells, misfolded proteins are still extracted from the ER, as has been reported for 3-Hydroxy-3-methylglutaryl-coenzyme A reductase in the cholesterol biosynthesis pathway (Morris et al., 2014), and that their removal from the ER alleviates the proteotoxic load.

Our study illustrates the power of our functional genomics approach to uncover biomarkers predictive of drug responses in patients and to guide the rational design of combination therapies that show promise to overcome the urgent clinical problem of drug resistance in cancer. From a clinical perspective, an assay that can predict response to a given therapy would significantly help improving outcomes and reduce toxicities for individual patients with MM. Currently, however, therapeutic decisions are largely based on a clinical trial-and-error basis. Our results support the development of clinical assays predictive of proteasome inhibitor sensitivity, with the potential to become an essential test in every-day treatment decisions for physicians treating patients with MM. The combination of 
observational genomics in patients and functional genomics in model systems can pave the way for precision medicine, while providing fundamental insights into biology.

\section{Materials and methods}

\section{Cell culture and drug treatments}

RPMI-8226, U-266 and JJN-3 cells were obtained from the German Collection of Microorganisms and Cell Culture (DSMZ, Braunschweig, Germany). K562 cells were a kind gift of Neil Shah (UCSF). RPMI8226, U-266 and K562 cells were grown in RPMI medium supplemented with $10 \%$ fetal bovine serum (FBS), 4 mM L-glutamine (L-glut) and antibiotics (pen/strep). JJN-3 cells were grown in a 50:50 mixture of Iscove's Modified Dulbecco's media (IMDM) and high-glucose Dulbecco's Modified Eagle's Medium (DMEM) supplemented with $20 \% \mathrm{FBS}$ and $4 \mathrm{mM} \mathrm{L-glut} \mathrm{and} \mathrm{pen/strep.} \mathrm{For} \mathrm{proteasome}$ inhibition studies, cells were treated (1) overnight (24 hr) with increasing doses of either carfilzomib (Onyx, South San Francisco, CA) or bortezomib (Selleck Chemicals, Houston, TX) to establish dose-response curves, or (2) for $1 \mathrm{hr}$ with a concentration of the proteasome inhibitor equal to its EC50, measured $24 \mathrm{hr}$ after the pulse exposure. Following the pulse exposure cells were washed twice with media and replated at a density of 0.5 million per milliliter. Exposure times and drug concentrations are indicated in the figures. To induce autophagy, cells were treated with $200 \mathrm{nM}$ rapamycin (EMD Millipore, Billerica, MA) or $100 \mathrm{mM} \mathrm{D-(+)-trehalose} \mathrm{dihydrate} \mathrm{(Sigm-Aldrich,}$ St. Louis, MO) overnight (24 hr). After exposure to the drug, the cells were pelleted and resuspended in media without rapamycin or trehalose and supplemented with increasing concentrations of carfilzomib and incubated for an additional $24 \mathrm{hr}$ to establish dose-response curves.

\section{Lentiviral and retroviral transductions}

The retroviral expression construct pBABE-puro mCherry-EGFP-LC3B was a gift from Jayanta Debnath (Addgene, Cambridge, MA], plasmid \# 22,418) (N'Diaye et al., 2009). Retroviral transductions were carried out by transfection of $16 \mu \mathrm{g}$ of retroviral vector and $2 \mu \mathrm{g}$ of a plasmid encoding the envelope protein VSV-G (Clontech Laboratories, Inc., Mountain View, CA) into the packaging cell line GP2-293 (Clontech) using lipofectamine 2000 (Life Technologies, Grand Island, NY). $24 \mathrm{hr}$ after transfection, the cells were switched to virus collection medium (DMEM supplemented with 4\% FBS, 15 mM HEPES and $2 \mathrm{mM} \mathrm{L-glut).} 24 \mathrm{hr}$ later (48 hr after transfection), high-titer retroviral supernatant was collected, filtered through a $0.45 \mu \mathrm{m}$ PVDF membrane and supplemented with $8 \mu \mathrm{g} / \mathrm{ml}$ polybrene. The supernatant was used immediately for infection of 2.5 million target cells at a density of 1 million cells per milliliter. Transduction was accomplished by spinoculating the cells at $2000 \mathrm{rpm}$. After Spinoculation, the cells were recovered, spun down and resuspended at $\sim 500,000$ cells per milliliter in the appropriate media. Lentiviral transductions were carried out as previously described (Kampmann et al., 2014).

\section{Primary shRNA screen}

Sublibraries of our next-generation shRNA library (Kampmann et al., 2015) targeting 7712 genes involved in proteostasis, cancer, apoptosis, kinases, phosphatases and drug targets were introduced into U-266 MM cells at an $\mathrm{MOI}$ of $\sim 0.3$ (ensuring that most cells express at most one shRNA). Cells transduced with the shRNA libraries were selected using puromycin. This population was split into two subpopulations. One was grown in the absence of drug, whereas the other was exposed to $1 \mathrm{hr}$ pulses of carfilzomib at a concentration around the LD50 measured at $24 \mathrm{hr}$ (150-200 nM), followed by recovery. After 4 rounds of treatment and recovery, treated and untreated cells were harvested, genomic DNA was isolated and the shRNA-encoding cassette was PCR-amplified and subjected to next-generation sequencing as previously described (Kampmann et al., 2014). Growth and carfilzomib resistance phenotypes were quantified and $p$ values for hit genes were calculated using gimap software (Kampmann et al., 2013, 2014) (http://gimap.ucsf.edu). Gene-based phenotypes were calculated by averaging the phenotypes of the 3 most extreme shRNAs targeting this gene, excluding shRNAs for which there were less than 50 sequencing reads in both the treated and the untreated population. This ad hoc metric is defined arbitrarily as a compromise between averaging fewer shRNAs (which may be too sensitive to outliers) and averaging too many shRNAs (which would include inactive shRNAs and thereby underestimate the effect size). 


\section{Validation screen}

An average of 3 shRNAs targeting selected hit genes were selected based on their activity in the primary screen and individually cloned to build a focused custom shRNA library. This library was introduced into U-266, JJN-3, RPMI-8226 and K562 cells. Cells were grown untreated, or treated with pulses of bortezomib, following a similar selection strategy as for the primary screen. Growth and bortezomib resistance phenotypes were quantified and phenotypes were averaged for shRNAs targeting the same gene using gimap software (Kampmann et al., 2013, 2014) (http://gimap.ucsf. edu). For individual validation experiments, a negative control shRNA (5'-CGTTCTTAGGGTGAG TAAGAAATAGTGAAGCCACAGATGTATTTCTTACTCACCCTAAGAACT-3'), an shRNA targeting PSDM12 (5'- CAGCCTITCTCTCAAATCTAGTTAGTGAAGCCACAGATGTAACTAGATTTGAGAGAAAGGCTT-3') or an shRNA targeting PSMB5 (5'-CGACGGTGAAGAAGGTGATAGATAGTGAAGCCACAGATGTATCTAT CACCTTCTTCACCGTCT-3') were expressed in the lentiviral vector pMK1200 (Kampmann et al., 2013) or pMK1224 (details provided on request).

\section{Other bioinformatic analysis}

For GO term enrichment analysis of hit genes from the primary screen, top hits were defined as follows: The 50 genes with the most sensitizing and most desensitizing gene phenotypes and a minimal $p$ value of $10^{-4}$ were defined as top sensitizing and desensitizing hits. GO term enrichment $p$ values were calculated using Database for Annotation, Visualization and Integrated Discovery (DAVID) (Huang et al., 2009a, 2009b), using the set of 7712 genes targeted by the sublibraries used in the primary screen as the background. Where different GO-terms encompassing the same subset of hit genes were found, only one is displayed. Similarly, where a GO term described a subset of hit genes of those described by another GO term that had a more significant $p$ value, only the more significant GO term describing a larger set of hit genes is displayed. For GO term enrichment analysis of proteins enriched based on proteome Stable Isotope Labeling by Amino Acids in Cell Culture (SILAC) experiments, the top 50 enriched proteins for each pair-wise comparison of samples was analyzed.

\section{Cell viability assays}

Cell viability assays were carried out using the CellTiter GLO kit (Promega Corp., Madison, WI) following manufacturer's recommendations. Raw luminescence signals were collected using a SpectraMax M5 plate reader (Molecular Devices, Sunnyvale, CA) and an integration time of 500 milliseconds. The raw counts were normalized as the percent of signal relative to untreated cells, or the percent maximum signal when comparing treatments with more than one drug. Sigmoidal dose-response curve fitting for EC50 calculation was performed using the Prism V5 package (GraphPad Software Inc., San Diego, CA).

\section{Immunoblotting}

Total cell lysates were collected in SDS sample buffer $(62.5 \mathrm{mM}$ Tris $\mathrm{pH} 6.8,10 \%$ glycerol, $2 \%$ SDS, $0.004 \%$ bromophenol blue). Lysates were sonicated for $\sim 15 \mathrm{~s}$ to shear the genomic DNA. 2-mercaptoethanol (2 ME) was added to a final concentration of $5 \%$ to the lysates just prior to boiling and loading on SDSPAGE gels. Gel loading normalization was accomplished by one of two methods: (1) same number of live cells per condition, or (2) densitometry after SDS-PAGE electrophoresis, transfer onto nitrocellulose membranes and staining with Ponceau stain. Normalized total cell lysate amounts were loaded onto precast Tris-glycine SDS-PAGE gels (BioRad), electrophoresed, and transferred onto $2.0 \mu \mathrm{m}$ pore nitrocellulose membranes. Equal loading per lane was verified by staining the membrane with Ponceau stain. Destained membranes were blocked for 1-2 hr in Tris-borate saline supplemented with $0.1 \%$ Tween 20 (TBST) and 5\% non-fat milk. Blocked membranes were incubated overnight with primary antibodies diluted in TBST supplemented with $5 \%$ bovine serum albumin. Antibodies and dilutions were as follows: anti-SOSTM1/p62 (D5E2) rabbit monoclonal antibody (Cell Signaling Technology [Danvers, MA] \#8025, 1:1000), anti-GAPDH rabbit polyclonal antibody (Abcam [Cambridge, MA] ab9485, 1:2000), anti-PSMD12 rabbit polyclonal antibody (Bethyl Laboratories Inc. [Montgomery, TX] \#A303-830A, 1:2000), anti-PSMB5 rabbit polyclonal antibody (Bethyl Laboratories, Inc., Montgomery, TX, \#A303-847A, 1:5000), anti-VCP/p97 rabbit polyclonal antibody (Cell Signaling Technology \#2648, 1:1000), anti-MCL1 (D35A5) rabbit monoclonal antibody (Cell Signaling Technology \#5453, 1:1000), anti-UFD1L rabbit polyclonal antibody (Bethyl Laboratories Inc. \#A301-875A 1:500), NFkB pathway antibodies (NFkB sample kit, Cell Signaling Technology \#9936, all at 1:1000). Membranes 
were incubated with HRP-conjugated secondary antibodies diluted in TBST supplemented with $5 \%$ nonfat milk at a 1:5000 dilution (Amersham, GE Healthcare Life Sciences [Pittsburgh, PA] NA931, NA934) for $1 \mathrm{hr}$ at room temperature. Blots were developed using luminol-based enhanced chemiluminescence substrates (SuperSignal West Dura Extended Duration Substrate, or SuperSignal West Femto Maximum Sensitivity Substrate, Life Technologies) and exposed to radiographic film or imaged directly in a digital gel imager (Chemidoc XRS+, BioRad). Digital images were automatically adjusted for contrast using the photo editor Adobe Photoshop (Adobe Systems, San Jose, CA). Densitometric quatification of immunoblots was performed using the software package ImageJ (National Institutes of Health, Bethesda, MD) (Schneider et al., 2012). The background subtracted area under the curve for each band was quantified and normalized to either total protein or loading controls.

\section{Proteasome activity assays}

U-266 cells were transduced with a negative control shRNA or an shRNA targeting PSMD12 (sequences as described above). Cell populations were then split and treated with different concentrations of carfilzomib for $1 \mathrm{hr}$ or left untreated. Proteasome activity was assayed in lysates of these cell populations using the ProCISE assay (Parlati et al., 2009) or the LLVY-AMC for chymotryptic activity (Boston Biochem, Cambridge, MA, \#S-280) following the manufacturer's instructions, except that a buffer consisting of $20 \mathrm{mM}$ Tris, $\mathrm{pH} 8.0,0.5 \mathrm{mM}$ EDTA without SDS was used.

\section{SILAC based quantification of protein levels and di-Gly-lysine modified peptides}

K562 cells expressing negative control shRNA or an inducible shRNA targeting PSMD6 (as used for proteasome activity assays) were grown for 7 days in medium containing either standard lysine and arginine (light isotopes), lysine (4,4,5,5-D4) and arginine (U-13C6) (medium isotopes) or lysine $(\mathrm{U}-13 \mathrm{C6}, \mathrm{U}-15 \mathrm{~N} 2)$ and arginine (U-13C6, U-15N4) (heavy isotopes) obtained from Cambridge Isotope laboratories (Cambridge, MA). shRNA expression was then induced for $48 \mathrm{hr}$, after which some cell populations were treated with bortezomib as described for the proteasome activity assays. Cells were combined in two triple-SILAC experiments as follows: Combination A: SILAC light: untreated negative-control; SILAC medium: bortezomib-treated ; SILAC heavy: PSMD6 knockdown and bortezomib-treated. Combination B: SILAC light: untreated negative-control; SILAC medium: PSMD6-knockdown no inhibitor; SILAC heavy: PSMD6-knockdown and bortezomib-treated. SILAC labeled cells were lysed with modified RIPA buffer $(50 \mathrm{mM}$ Tris- $\mathrm{HCl} \mathrm{pH} 7.5,150 \mathrm{mM} \mathrm{NaCl}, 1 \%$ Nonidet P-40, 0.1\% sodium-deoxycholate, $1 \mathrm{mM}$ EDTA) containing protease inhibitors (Complete protease inhibitor mixture tablets, Roche Diagnostics, Indianapolis, IN) and N-ethylmaleimide $(5 \mathrm{mM})$. The lysates were incubated for $10 \mathrm{~min}$ on ice and subsequently cleared by centrifugation at $16,000 \times \mathrm{g}$. An equal amount of protein was mixed from different SILAC states and proteins were precipitated by adding chilled acetone (final concentration $80 \%$ ) and storing overnight at $-20^{\circ} \mathrm{C}$. Proteins were redissolved in denaturing buffer (6 M urea, $2 \mathrm{M}$ thiourea, $10 \mathrm{mM} \mathrm{HEPES} \mathrm{pH} \mathrm{8.0)} \mathrm{and}$ subsequently reduced with dithiothreitol $(1 \mathrm{mM})$ and alkylated with chloroacetamide $(5.5 \mathrm{mM})$. Proteins were proteolysed with Lysyl endoproteinase C (Lys-C) for $6 \mathrm{hr}$ and after fourfold dilution in water with trypsin overnight. The digestion was stopped by addition of trifluoroacetic acid, incubated at $4^{\circ} \mathrm{C}$ for $2 \mathrm{hr}$ and resulting precipitates removed by centrifugation for $15 \mathrm{~min}$ at $4000 \times \mathrm{g}$. Cleared peptides were purified by reversed-phase Sep-Pak C18 cartridges (Waters Corporation, Milford, MA). Di-Gly-lysine containing peptides were enriched using the Ubiquitin Remnant Motif Kit (Cell Signaling Technology), according to the manufacturer's protocol. In brief, peptides were eluted from the Sep-Pak C18 cartridges and incubated with $40 \mu \mathrm{l}$ of anti-di-Gly-lysine antibody resin in $1 \mathrm{X}$ immunoaffinity purification (IAP) buffer on a rotational wheel for $4 \mathrm{hr}$ at $4^{\circ} \mathrm{C}$ (Wagner et al., 2011). After centrifugation, the supernatant (containing unbound peptides) was removed and used for proteome analysis (see below). The immunoenriched peptides were washed three times with 1X IAP buffer and two times with water. Peptides were eluted with $0.15 \%$ trifluoroacetic acid in water. Eluted peptides were fractionated into 6 fractions by micro-column-based strong-cation exchange chromatography (SCX) and desalted by reversed phase C18 Stage-tips. Similarly, for analysis of protein levels, unbound peptides from the anti-di-Gly-lysine enrichment (see above) were fractioned by micro-SCX and purified by reversed phase C18 Stage-tips. 


\section{Mass spectrometry and data analysis}

Peptide fractions were analyzed on a quadrupole Orbitrap (Q Exactive, Thermo Scientific, Waltham, MA) mass spectrometer equipped with a nanoflow HPLC system (Thermo Scientific). Peptides were loaded onto C18 reversed-phase columns and eluted with a linear gradient from $8 \%$ to $40 \%$ acetonitrile containing $0.5 \%$ acetic acid. The mass spectrometer was operated in a data-dependent mode, automatically switching between MS and MS/MS. Survey full scan MS spectra ( $\mathrm{m} / \mathrm{z}$ 300-1200) were acquired in the Orbitrap mass analyzer. The 10 most intense ions were sequentially isolated and fragmented by higher-energy C-trap dissociation (HCD). Peptides with an unassigned charge state, as well as peptides with a charge state less than +2 for proteome samples, and +3 for di-glycine-lysine enriched samples, were excluded from fragmentation. Fragment spectra were acquired in the Orbitrap mass analyzer. Raw MS data files were analyzed by the MaxQuant software version 1.4.1.1 (Cox and Mann, 2008). Parent ion and MS/MS spectra were searched against protein sequences from the UniProt knowledge database using the Andromeda search engine. Spectra were searched with a mass tolerance of $6 \mathrm{ppm}$ in the MS mode, $20 \mathrm{ppm}$ for the MS/MS mode, strict trypsin specificity allowing up to two missed cleavage sites. Cysteine carbamidomethylation was searched as a fixed modification. Aminoterminal protein acetylation, methionine oxidation and $\mathrm{N}$-ethylmaleimide modification of cysteines, and di-Gly-lysine were searched as variable modifications, and di-Gly-lysines were required to be located internally in the peptide sequence. Site localization probabilities were determined by MaxQuant using a post-translational modification scoring algorithm as described previously (Cox and Mann, 2008). Using the target-decoy search strategy (Elias and Gygi, 2007) and a posterior error probability filter, a false discovery rate of less than one percent was achieved.

\section{Proteasome and aggresome detection in plasma cells of myeloma patients}

23 patients on a clinical research protocol using carfilzomib, lenalidomide, and dexamethasone (CRd) treatment in newly diagnosed MM patients were evaluated at the National Institute of Health $\mathrm{NIH}$, Bethesda, MD). Patients were tested for the expression of 195 and $20 \mathrm{~S}$ proteosome subunits and aggresome levels in bone marrow plasma cells before start of carfilzomib therapy. Bone marrow aspirates were collected and immunostained using antibodies against CD45, CD38, CD138 (Becton Dickinson, San Jose, CA), Proteasome 19S S7 (19S) and Proteasome Subunit Beta Type 4 (beta4) (Abcam, Cambridge, UK). The antibody used for immunodetection of the S7 subunit of the $19 \mathrm{~S}$ proteasome was previously validated (Rousseau et alo, 2009). In parallel, cells were labeled with ProteoStat Aggresome Detection Reagent (Enzo Life Sciences, Farmingdale, NY). Multicolor acquisition and analysis was performed using BD FACS CANTO II and DIVA software. Data was expressed as mean fluorescence intensity (MFI) ratio using isotype-matched controls. Statistical analysis was performed using Excel (Microsoft Corporation, Redmond, WA) and DataPrism (Seattle, WA) software.

\section{qRT-PCR}

U-266 cells carrying a constitutive non-targeting shRNA or an shRNA targeting the 19S subunit PSMD12 were collected by centrifugation, washed twice with ice-cold PBS and lysed in TRIzol (Life Techologies, Grand Island, NY). RNA was extracted following manufacturer's recommendations. $500 \mathrm{ng}$ of total RNA were reverse transcribed using the SuperScript VILO cDNA synthesis kit (Life Technologies) following manufacturer's recommendations. The resulting cDNA reactions were diluted 10 -fold with $10 \mathrm{mM}$ Tris $\mathrm{pH} 8.0$ and $1 \%$ of this dilution was used for each quantitative real-time PCR (qPCR) reaction. qPCR reactions were set-up using IO SYBR Geen Super Mix (BioRad, Hercules, CA) in $20 \mu$ reactions. The reactions were ran on a BioRad CFX96 Real Time system (BioRad) and analyzed using the CFX Manager Software V3.0 (BioRad). All reactions were normalized to an internal loading control (GAPDH) and the fold-changes reflecting the extent of knockdown were then normalized to the no drug, negative control shRNA condition. Average values for three different oligonucleotide pairs targeting the PSMD12 trasncript were taken for the calculations. The following oligonucleotides taregting human transcripts were used: Hs_GAPDH_Fwd: 5'-AGCCACATCGCTCAGACAC-3', Hs_GAPDH_Rev: 5'-TGGAAGATGG TGATGGGATT-3', Hs_PSMD12_exon9-3'UTR_Fwd: 5'- AATGAAAAGGATGGCACAGC-3', Hs_PSMD12_exon93'UTR_Rev: 5'- TITGGATCCTTGGGTCTCTG-3', Hs_PSMD12_RefSeq_Var1_Fwd: 5'- CGTCAAGATGGAGGTG GACT-3', Hs_PSMD12_RefSeq_Var1_Rev: 5'- TCCAGAGAGAGAAGGGTTTCA-3', Hs_PSMD12_exon13_Fwd: 5'-CGTCAAGATGGAGGTGGACT-3', Hs_PSMD12_exon1-3_Rev: 5'- AGATACGGGATGTCGA TACCA-3' 


\section{Acknowledgements}

We are grateful to Brian Tuch (then at Onyx Pharmaceuticals, an Amgen subsidiary), Marc Shuman (UCSF), Cammie Edwards (UCSF), Owen Chen (UCSF) and members of the Walter and Weissman labs for insightful discussions and technical assistance. This work was supported by the Onyx-UCSF Oncology Innovation Alliance (DAA, MK, JSW, PW), the Howard Hughes Medical Institute Collaborative Innovation Alliance (JSW, PW), NIH/NCI U01 CA168370 (JSW), an Irvington Postdoctoral Fellowship of the Cancer Research Institute (DAA), Jane Coffins Child Postdoctoral Fellowship and $\mathrm{NIH} / \mathrm{NCl}$ Pathway to Independence Award K99/R00 CA181494 (MK). CC is supported by Hallas Møller Investigator and Sapere Aude research grants from the Novo Nordisk Foundation and the Danish Council for Independent research, respectively. Center for Protein Research is supported by a generous donation from the Novo Nordisk Foundation (grant number: NNF14CC0001).

\section{Additional information}

Competing interests

TJB: is an employee of Onyx Pharmaceuticals, an Amgen subsidiary. AGL: is an employee of Onyx Pharmaceuticals, an Amgen subsidiary. The authors declare that no competing interests exist.

Funding

\begin{tabular}{|c|c|c|}
\hline Funder & Grant reference & Author \\
\hline $\begin{array}{l}\text { Howard Hughes Medical } \\
\text { Institute }\end{array}$ & $\begin{array}{l}\text { Collaborative Innovation } \\
\text { Alliance }\end{array}$ & $\begin{array}{l}\text { Peter Walter, Jonathan S } \\
\text { Weissman }\end{array}$ \\
\hline $\begin{array}{l}\text { National Institutes of } \\
\text { Health }\end{array}$ & $\begin{array}{l}\text { Pathway to Independence } \\
\text { Award K99/R00 CA181494 }\end{array}$ & Martin Kampmann \\
\hline $\begin{array}{l}\text { University of California at } \\
\text { San Francisco }\end{array}$ & $\begin{array}{l}\text { Onyx- Oncology } \\
\text { Innovation Alliance }\end{array}$ & $\begin{array}{l}\text { Martin Kampmann, Diego } \\
\text { Acosta-Alvear, Peter } \\
\text { Walter, Jonathan S } \\
\text { Weissman }\end{array}$ \\
\hline Cancer Research Institute & $\begin{array}{l}\text { Irvington Postdoctoral } \\
\text { Fellowship }\end{array}$ & Diego Acosta-Alvear \\
\hline $\begin{array}{l}\text { Jane Coffin Childs } \\
\text { Memorial Fund for } \\
\text { Medical Research }\end{array}$ & Postdoctoral Fellowship & Martin Kampmann \\
\hline Novo Nordisk & Hallas Møller Investigator & Chunaram Choudhary \\
\hline Det Frie Forskningsråd & $\begin{array}{l}\text { Sapere Aude research } \\
\text { grant }\end{array}$ & Chunaram Choudhary \\
\hline $\begin{array}{l}\text { National Institutes of } \\
\text { Health }\end{array}$ & U01 CA168370 & Jonathan S Weissman \\
\hline
\end{tabular}

The funders had no role in study design, data collection and interpretation, or the decision to submit the work for publication.

\section{Author contributions}

DA-A, Conception and design, Acquisition of data, Analysis and interpretation of data, Drafting or revising the article; MYC, TW, TJB, AGL, Acquisition of data, Analysis and interpretation of data; OS, $\mathrm{JH}$, Acquisition of data; NK, OL, IM, CC, Conception and design, Analysis and interpretation of data; PW, Conception and design, Drafting or revising the article; JSW, Conception and design, Drafting or revising the article, Contributed unpublished essential data or reagents; MK, Conception and design, Acquisition of data, Analysis and interpretation of data, Drafting or revising the article, Contributed unpublished essential data or reagents

Author ORCIDs

Martin Kampmann, (D) http://orcid.org/0000-0002-3819-7019

Ethics

Clinical trial registration NCT01402284

Human subjects: The registered clinical research trial (NCT01402284) was approved by the National Cancer Institute (NCI) Institutional Review Board (IRB) and complied with the Declaration of Helsinki, 
the International Conference on Harmonization, and the Guidelines for Good Clinical Practice. All enrolled patients meeting criteria were consented with an IRB-approved document.

\section{Additional files}

Supplementary files

- Supplementary file 1. Growth phenotypes from shRNA screen.

DOI: 10.7554/eLife.08153.014

- Supplementary file 2. Carfilzomib phenotypes from shRNA screen. DOI: 10.7554/eLife.08153.015

- Supplementary file 3. Proteome changes from SILAC experiments. DOI: 10.7554/eLife.08153.016

- Supplementary file 4. Ubiquitylome changes from SILAC experiments. DOI: $10.7554 /$ eLife.08153.017

\section{References}

Balch WE, Morimoto RI, Dillin A, Kelly JW. 2008. Adapting proteostasis for disease intervention. Science 319:916-919. doi: 10.1126/science.1141448.

Bianchi G, Oliva L, Cascio P, Pengo N, Fontana F, Cerruti F, Orsi A, Pasqualetto E, Mezghrani A, Calbi V, Palladini G, Giuliani N, Anderson KC, Sitia R, Cenci S. 2009. The proteasome load versus capacity balance determines apoptotic sensitivity of multiple myeloma cells to proteasome inhibition. Blood 113:3040-3049. doi: 10.1182/ blood-2008-08-172734.

Braunstein MJ, Scott SS, Scott CM, Behrman S, Walter P, Wipf P, Coplan JD, Chrico W, Joseph D, Brodsky JL, Batuman O. 2011. Antimyeloma effects of the heat shock protein 70 molecular chaperone inhibitor MAL3-101. Journal of Oncology 2011:232037. doi: 10.1155/2011/232037.

Breslow DK, Cameron DM, Collins SR, Schuldiner M, Stewart-Ornstein J, Newman HW, Braun S, Madhani HD, Krogan NJ, Weissman JS. 2008. A comprehensive strategy enabling high-resolution functional analysis of the yeast genome. Nature Methods 5:711-718. doi: 10.1038/nmeth.1234.

Buac D, Shen M, Schmitt S, Kona FR, Deshmukh R, Zhang Z, Neslund-Dudas C, Mitra B, Dou QP. 2013. From bortezomib to other inhibitors of the proteasome and beyond. Current Pharmaceutical Design 19:4025-4038. doi: 10.2174/1381612811319220012.

Cenci S, Oliva L, Cerruti F, Milan E, Bianchi G, Raule M, Mezghrani A, Pasqualetto E, Sitia R, Cascio P. 2012. Pivotal Advance: protein synthesis modulates responsiveness of differentiating and malignant plasma cells to proteasome inhibitors. Journal of Leukocyte Biology 92:921-931. doi: 10.1189/jlb.1011497.

Chen S, Blank JL, Peters T, Liu XJ, Rappoli DM, Pickard MD, Menon S, Yu J, Driscoll DL, Lingaraj T, Burkhardt AL, Chen W, Garcia K, Sappal DS, Gray J, Hales P, Leroy PJ, Ringeling J, Rabino C, Spelman JJ, Morgenstern JP, Lightcap ES. 2010. Genome-wide siRNA screen for modulators of cell death induced by proteasome inhibitor bortezomib. Cancer Research 70:4318-4326. doi: 10.1158/0008-5472. CAN09-4428.

Cox J, Mann M. 2008. MaxQuant enables high peptide identification rates, individualized p.p.b.-range mass accuracies and proteome-wide protein quantification. Nature Biotechnology 26:1367-1372. doi: 10.1038/nbt.1511. Demchenko YN, KuehI WM. 2010. A critical role for the NFkB pathway in multiple myeloma. Oncotarget 1:59-68. doi: 10.18632/oncotarget.109.

Durie BG, Harousseau JL, Miguel JS, Bladé J, Barlogie B, Anderson K, Gertz M, Dimopoulos M, Westin J, Sonneveld P, Ludwig H, Gahrton G, Beksac M, Crowley J, Belch A, Boccadaro M, Cavo M, Turesson I, Joshua D, Vesole D, Kyle R, Alexanian R, Tricot G, Attal M, Merlini G, Powles R, Richardson P, Shimizu K, Tosi P, Morgan G, Rajkumar SV, International Myeloma Working Group. 2006. International uniform response criteria for multiple myeloma. Leukemia 20:1467-1473. doi: 10.1038/sj.leu.2404284.

Elias JE, Gygi SP. 2007. Target-decoy search strategy for increased confidence in large-scale protein identifications by mass spectrometry. Nature Methods 4:207-214. doi: 10.1038/nmeth1019.

Giaever G, Shoemaker DD, Jones TW, Liang H, Winzeler EA, Astromoff A, Davis RW. 1999. Genomic profiling of drug sensitivities via induced haploinsufficiency. Nature Genetics 21:278-283. doi: 10.1038/6791.

Gorbea C, Goellner GM, Teter K, Holmes RK, Rechsteiner M. 2004. Characterization of mammalian Ecm29, a 26 S proteasome-associated protein that localizes to the nucleus and membrane vesicles. The Journal of Biological Chemistry 279:54849-54861. doi: 10.1074/jbc.M410444200.

Huang DW, Sherman BT, Lempicki RA. 2009a. Systematic and integrative analysis of large gene lists using DAVID bioinformatics resources. Nature Protocols 4:44-57. doi: 10.1038/nprot.2008.211.

Huang DW, Sherman BT, Lempicki RA. 2009b. Bioinformatics enrichment tools: paths toward the comprehensive functional analysis of large gene lists. Nucleic Acids Research 37:1-13. doi: 10.1093/nar/gkn923.

Huber EM, Heinemeyer W, Groll M. 2015. Bortezomib-resistant mutant proteasomes: structural and biochemical evaluation with carfilzomib and ONX 0914. Structure 23:407-417. doi: 10.1016/j.str.2014.11.019. 
Ishii T, Seike T, Nakashima T, Juliger S, Maharaj L, Soga S, Akinaga S, Cavenagh J, Joel S, Shiotsu Y. 2012. Anti-tumor activity against multiple myeloma by combination of KW-2478, an Hsp90 inhibitor, with bortezomib. Blood Cancer J 2:e68. doi: 10.1038/bcj.2012.13.

Kampmann M, Bassik MC, Weissman JS. 2013. Integrated platform for genome-wide screening and construction of high-density genetic interaction maps in mammalian cells. Proceedings of the National Academy of Sciences of USA 110:E2317-E2326. doi: 10.1073/pnas.1307002110.

Kampmann M, Bassik MC, Weissman JS. 2014. Functional genomics platform for pooled screening and generation of mammalian genetic interaction maps. Nature Protocols 9:1825-1847. doi: 10.1038/nprot.2014.103.

Kampmann M, Horlbeck MA, Chen Y, Tsai JC, Bassik MC, Gilbert LA, Villalta JE, Kwon SC, Chang H, Kim VN, Weissman JS. 2015. Next-generation libraries for robust RNA interference-based genome-wide screens. Proceedings of the National Academy of Sciences of USA 112:E3384-E3391. doi: 10.1073/pnas.1508821112.

Kawaguchi T, Miyazawa K, Moriya S, Ohtomo T, Che XF, Naito M, Itoh M, Tomoda A. 2011. Combined treatment with bortezomib plus bafilomycin A1 enhances the cytocidal effect and induces endoplasmic reticulum stress in U266 myeloma cells: crosstalk among proteasome, autophagy-lysosome and ER stress. International Journal of Oncology 38:643-654. doi: 10.3892/ijo.2010.882.

Komatsu S, Moriya S, Che XF, Yokoyama T, Kohno N, Miyazawa K. 2013. Combined treatment with SAHA, bortezomib, and clarithromycin for concomitant targeting of aggresome formation and intracellular proteolytic pathways enhances ER stress-mediated cell death in breast cancer cells. Biochemical and Biophysical Research Communications 437:41-47. doi: 10.1016/j.bbrc.2013.06.032.

Korde N, Roschewski M, Zingone A, Kwok M, Manasanch EE, Bhutani M, Tageja N, Kazandjian D, Mailankody S, Wu P, Morrison C, Costello R, Zhang Y, Burton D, Mulquin M, Zuchlinski D, Lamping L, Carpenter A, Wall Y, Carter G, Cunningham SC, Gounden V, Sissung TM, Peer C, Maric I, Calvo KR, Braylan R, Yuan C, StetlerStevenson M, Arthur DC, Kong KA, Weng L, Faham M, Lindenberg L, Kurdziel K, Choyke P, Steinberg SM, Figg W, Landgren O. 2015. Treatment with carfilzomib-lenalidomide-dexamethasone with lenalidomide extension in patients with smoldering or newly diagnosed multiple myeloma. JAMA Oncology 1:746-754. doi: 10.1001/ jamaoncol.2015.2010.

Liu C-W, Jacobson AD. 2013. Functions of the 19S complex in proteasomal degradation. Trends in Biochemical Sciences 38:103-110. doi: 10.1016/j.tibs.2012.11.009.

Mateos MV, Hernández MT, Giraldo P, de la Rubia J, de Arriba F, López Corral L, Rosiñol L, Paiva B, Palomera L, Bargay J, Oriol A, Prosper F, López J, Olavarría E, Quintana N, García JL, Bladé J, Lahuerta JJ, San Miguel JF. 2013. Lenalidomide plus dexamethasone for high-risk smoldering multiple myeloma. The New England Journal of Medicine 369:438-447. doi: 10.1056/NEJMoa1300439.

Matheny CJ, Wei MC, Bassik MC, Donnelly AJ, Kampmann M, Iwasaki M, Piloto O, Solow-Cordero DE, Bouley DM, Rau R, Brown P, McManus MT, Weissman JS, Cleary ML. 2013. Next-generation NAMPT inhibitors identified by sequential high-throughput phenotypic chemical and functional genomic screens. Chemistry \& Biology 20:1352-1363. doi: 10.1016/j.chembiol.2013.09.014.

Meister S, Schubert U, Neubert K, Herrmann K, Burger R, Gramatzki M, Hahn S, Schreiber S, Wilhelm S, Herrmann M, Jäck HM, Voll RE. 2007. Extensive immunoglobulin production sensitizes myeloma cells for proteasome inhibition. Cancer Research 67:1783-1792. doi: 10.1158/0008-5472.CAN-06-2258.

Mishima Y, Santo L, Eda H, Cirstea D, Nemani N, Yee AJ, O’Donnell E, Selig MK, Quayle SN, Arastu-Kapur S, Kirk C, Boise LH, Jones SS, Raje N. 2015. Ricolinostat (ACY-1215) induced inhibition of aggresome formation accelerates carfilzomib-induced multiple myeloma cell death. British Journal of Haematology 169:423-434. doi: 10.1111/bjh.13315.

Moriya S, Che XF, Komatsu S, Abe A, Kawaguchi T, Gotoh A, Inazu M, Tomoda A, Miyazawa K. 2013. Macrolide antibiotics block autophagy flux and sensitize to bortezomib via endoplasmic reticulum stressmediated CHOP induction in myeloma cells. International Journal of Oncology 42:1541-1550. doi: 10.3892/ ijo.2013.1870.

Morris LL, Hartman IZ, Jun D-J, Seemann J, DeBose-Boyd RA. 2014. Sequential actions of the AAA-ATPase valosin-containing protein (VCP)/p97 and the proteasome $19 \mathrm{~S}$ regulatory particle in sterol-accelerated, endoplasmic reticulum (ER)-associated degradation of 3-hydroxy-3-methylglutaryl-coenzyme A reductase. The Journal of Biological Chemistry 289:19053-19066. doi: 10.1074/jbc.M114.576652.

N'Diaye E-N, Kajihara KK, Hsieh I, Morisaki H, Debnath J, Brown EJ. 2009. PLIC proteins or ubiquilins regulate autophagy-dependent cell survival during nutrient starvation. EMBO Reports 10:173-179. doi: 10.1038/embor. 2008.238.

Nathan JA, Spinnenhirn V, Schmidtke G, Basler M, Groettrup M, Goldberg AL. 2013. Immuno- and constitutive proteasomes do not differ in their abilities to degrade ubiquitinated proteins. Cell 152:1184-1194. doi: 10.1016/ j.cell.2013.01.037.

Oerlemans R, Franke NE, Assaraf YG, Cloos J, van Zantwijk I, Berkers CR, Scheffer GL, Debipersad K, Vojtekova K, Lemos C, van der Heijden JW, Ylstra B, Peters GJ, Kaspers GL, Dijkmans BA, Scheper RJ, Jansen G. 2008.

Molecular basis of bortezomib resistance: proteasome subunit beta5 (PSMB5) gene mutation and overexpression of PSMB5 protein. Blood 112:2489-2499. doi: 10.1182/blood-2007-08-104950.

Pankiv S, Clausen TH, Lamark T, Brech A, Bruun J-A, Outzen H, Øvervatn A, Bjørkøy G, Johansen T. 2007. p62/ SQSTM1 binds directly to Atg8/LC3 to facilitate degradation of ubiquitinated protein aggregates by autophagy. The Journal of Biological Chemistry 282:24131-24145. doi: 10.1074/jbc.M702824200.

Parlati F, Lee SJ, Aujay M, Suzuki E, Levitsky K, Lorens JB, Micklem DR, Ruurs P, Sylvain C, Lu Y, Shenk KD, Bennett MK. 2009. Carfilzomib can induce tumor cell death through selective inhibition of the chymotrypsin-like activity of the proteasome. Blood 114:3439-3447. doi: 10.1182/blood-2009-05-223677. 
Radhakrishnan SK, Lee CS, Young P, Beskow A, Chan JY, Deshaies RJ. 2010. Transcription factor Nrf1 mediates the proteasome recovery pathway after proteasome inhibition in mammalian cells. Molecular Cell 38:17-28. doi: 10.1016/j.molcel.2010.02.029.

Rousseau E, Kojima R, Hoffner G, Djian P, Bertolotti A. 2009. Misfolding of proteins with a polyglutamine expansion is facilitated by proteasomal chaperones. The Journal of Biological Chemistry 284:1917-1929. doi: 10. 1074/jbc.M806256200.

Röllig C, Knop S, Bornhäuser M. 2014. Multiple myeloma. Lancet 385:2197-2208. doi: 10.1016/S0140-6736(14) 60493-1.

Santo L, Hideshima T, Kung AL, Tseng JC, Tamang D, Yang M, Jarpe M, van Duzer JH, Mazitschek R, Ogier WC, Cirstea D, Rodig S, Eda H, Scullen T, Canavese M, Bradner J, Anderson KC, Jones SS, Raje N. 2012. Preclinical activity, pharmacodynamic, and pharmacokinetic properties of a selective HDAC6 inhibitor, ACY-1215, in combination with bortezomib in multiple myeloma. Blood 119:2579-2589. doi: 10.1182/blood-2011-10-387365.

Sarkar S. 2013. Regulation of autophagy by mTOR-dependent and mTOR-independent pathways: autophagy dysfunction in neurodegenerative diseases and therapeutic application of autophagy enhancers. Biochemical Society Transactions 41:1103-1130. doi: 10.1042/BST20130134.

Sarkar S, Davies JE, Huang Z, Tunnacliffe A, Rubinsztein DC. 2007. Trehalose, a novel mTOR-independent autophagy enhancer, accelerates the clearance of mutant huntingtin and alpha-synuclein. The Journal of Biological Chemistry 282:5641-5652. doi: 10.1074/jbc.M609532200.

Schmidt M, Finley D. 2014. Regulation of proteasome activity in health and disease. Biochimica et Biophysica Acta 1843:13-25. doi: 10.1016/j.bbamcr.2013.08.012.

Schneider CA, Rasband WS, Eliceiri KW. 2012. NIH Image to ImageJ: 25 years of image analysis. Nature Methods 9:671-675. doi: 10.1038/nmeth.2089.

Schwickart M, Huang X, Lill JR, Liu J, Ferrando R, French DM, Maecker H, O'Rourke K, Bazan F, Eastham-Anderson J, Yue P, Dornan D, Huang DC, Dixit VM. 2010. Deubiquitinase USP9X stabilizes MCL1 and promotes tumour cell survival. Nature 463:103-107. doi: 10.1038/nature08646.

Shah JJ, Orlowski RZ. 2009. Proteasome inhibitors in the treatment of multiple myeloma. Leukemia 23:1964-1979. doi: 10.1038/leu.2009.173.

Steffen J, Seeger M, Koch A, Krüger E. 2010. Proteasomal degradation is transcriptionally controlled by TCF11 via an ERAD-dependent feedback loop. Molecular Cell 40:147-158. doi: 10.1016/j.molcel.2010.09.012.

Suraweera A, Münch C, Hanssum A, Bertolotti A. 2012. Failure of amino acid homeostasis causes cell death following proteasome inhibition. Molecular Cell 48:242-253. doi: 10.1016/j.molcel.2012.08.003.

Suzuki R, Hideshima T, Mimura N, Minami J, Ohguchi H, Kikuchi S, Yoshida Y, Gorgun G, Cirstea D, Cottini F, Jakubikova J, Tai YT, Chauhan D, Richardson PG, Munshi NC, Utsugi T, Anderson KC. 2015. Anti-tumor activities of selective HSP90 $\alpha / \beta$ inhibitor, TAS-116, in combination with bortezomib in multiple myeloma. Leukemia 29:510-514. doi: 10.1038/leu.2014.300.

Vogl DT, Stadtmauer EA, Tan KS, Heitjan DF, Davis LE, Pontiggia L, Rangwala R, Piao S, Chang YC, Scott EC, Paul TM, Nichols CW, Porter DL, Kaplan J, Mallon G, Bradner JE, Amaravadi RK. 2014. Combined autophagy and proteasome inhibition: a phase 1 trial of hydroxychloroquine and bortezomib in patients with relapsed/refractory myeloma. Autophagy 10:1380-1390. doi: 10.4161/auto.29264.

Wagner SA, Beli P, Weinert BT, Nielsen ML, Cox J, Mann M, Choudhary C. 2011. A proteome-wide, quantitative survey of in vivo ubiquitylation sites reveals widespread regulatory roles. Molecular \& Cellular Proteomics 10:M111.013284. doi: 10.1074/mcp.M111.013284.

Wolf DH, Stolz A. 2012. The Cdc48 machine in endoplasmic reticulum associated protein degradation. Biochimica et Biophysica Acta 1823:117-124. doi: 10.1016/j.bbamcr.2011.09.002.

Zhu YX, Tiedemann R, Shi CX, Yin H, Schmidt JE, Bruins LA, Keats JJ, Braggio E, Sereduk C, Mousses S, Stewart AK. 2011. RNAi screen of the druggable genome identifies modulators of proteasome inhibitor sensitivity in myeloma including CDK5. Blood 117:3847-3857. doi: 10.1182/blood-2010-08-304022. 